\title{
To Modernize or Not to Modernize - There is No Question
}

\author{
Slađana Živković \\ Technical College of Vocational studies \& Faculty of Civil Engineering and Architecture \\ University of Niš, Serbia \\ Nadežda Stojković \\ Faculty of Electrical Engineering, University of Niš, Serbia
}

\section{Doi:10.5901/ajis.2013.v2n11p70}

\begin{abstract}
The present paper has reported on modernization of foreign language teaching/learning process through the theoretical framework of constructivism. It has described some of the advantages of digital technologies, and how the Internet can be used in the foreign language classroom. Modern technologies are one of the necessities of the educational system in digital society, and have become a prerequisite to the modernization of education. The Internet, as a powerful information and communication technology resource, helps us to understand the world we live in, and it gives a new dimension to foreign language teaching/learning process. The 21st century education requires critical thinking, accurate and efficient problem solving, effective communication skills, collaboration and team work, creativity, innovative skills, technology skills, and lifelong learning. According to constructivism, learning is no longer seen simply as the result of the transmission of knowledge; it is an active process of constructing knowledge supported by various perspectives within meaningful and authentic contexts and interactions with the environment. The Internet is used to fit the requirements of goals in order to be effective within the constructivist learning environment.
\end{abstract}

Keywords: digital technologies, foreign language, constructivism, teacher/student role, learning environment

\section{Introduction}

Today's globalized and technology-driven world requires graduates to have in-depth knowledge and to be able to use this knowledge to solve real-world problems. So, to produce such graduates, it is needed to reexamine teaching and learning concepts. To meet the challenges, we propose new trends in modernization of educational system to be more open and to create a competitive (both globally and locally) standards and quality of education theory and practice (Živković \& Stojković, 2011). Preparing students to be good problem-solvers, critical thinkers, and lifelong learners has become an important educational goal in the twenty-first century (Bransford et al., 2000).

The use of modern technologies within foreign language teaching and learning process is a current challenge forcing to rethink a number of educational issues, such as, learner's autonomy, collaboration, motivation, creativity, as well as the enhancement of cognitive power of students during thinking and problem solving. Constructivism provides a good starting point for new learning model aimed at supporting students to reach their full potential.

According to constructivism, learning is no longer seen simply as the result of the transmission of knowledge; it is an active process of constructing knowledge supported by various perspectives within meaningful and authentic contexts and interactions with the environment. The environment creates students' engagement and content-relevant experiences by utilizing modern technologies and resources to support unique learning goals and knowledge construction (Young, 2003). Modern technologies provide an array of powerful tools that may help in transforming the traditional teachercentred and text-bound classrooms into student-focused, interactive knowledge environments.

\section{Digital Technologies in the Constructivist Foreign Language Classroom}

Current global trends in education contribute to the modernization of educational system and the improvement of the quality of foreign language teaching and learning process in order to respond to labour market demands (Stojković \& Živković, 2012). In redesigning the traditional methods and approaches to foreign language acquisition, and to motivate 
students and improve their attitudes toward the world, modern technologies, primarily computers and the Internet, play a prominent role. Increasingly, these technologies are being integrated in the area of foreign language teaching and learning activities. Their effective integration into the classroom has the potential to support educational goals.

As Jonassen (1995) argues, technologies should be used as knowledge construction tools by learners who learn with technology, not from it.

Technologies function as cognitive tools (Salomon, 1993) or mind tools (Jonassen, 2000).

The computer (together with the Internet) is an example of the digital mediating technology which role in education should not be viewed as add ons, but has been largely viewed as an instructional tool for providing a richer and more exciting learning environment (Duffy \& Cunningham, 1996).

There is no doubt that the computer helps build knowledge bases, which will "engage the learners more and result in more meaningful and transferable knowledge... Learners function as designers using the technology as tools for analyzing the world, accessing information, interpreting and organizing their personal knowledge, and representing what they know to others" (Jonassen \& Reeves, 1996).

Moreover, "technology is seen as an integral part of the cognitive activity. This view of distributed cognition significantly impacts how we think of the role of technology in education and training, the focus is not on the individual in isolation and what he or she knows, but on the activity in the environment. It is the activity - focused and contextualized that is central... The process of construction is directed towards creating a world that makes sense to us, that is adequate for our everyday functioning" (Duffy \& Cunningham, 1996). Obviously, technology is the enabling factor in order to implement constructivist principles (Duffy \& Cunningham, 1996; Jonassen, 1999).

If used wisely, computers and the Internet could add relevance and meaning to learning because they have the potential to increase student motivation for studying languages by letting them to decide on activities, materials and contents matched to their interests and learning styles, enhance the quality of work, promote access to resources, positively impact student learning, and promote student metacognitive skills (Heafner \& McCoy, 2001).

As we can conclude, constructivist pedagogical principles coupled with appropriate technology integration show the potential for major improvements in foreign language teaching and learning practices. They together provide opportunity to make and remake the concept of learning, and bring new directions for teaching and learning. They can allow learners to work to their fullest potential.

\subsection{A computer as a cognitive and metacognitive tool}

The most important role of today's technologies in education is to enhance cognitive and metacognitive skills, so, in this way, learners are engaged in meaningful learning and higher-order thinking. Cognitive and metacognitive skills are closely intertwined and dependent upon each other (Livingston, 1997). Cognitive skills refer to thinking (including knowing, perceiving, recognizing, conceiving, and reasoning), whereas metacognitive skills represent "thinking about thinking". Metacognitive skills can be described as understanding, analysis and "monitoring of cognitive processes" (Flavell, 1979). The generalizability of metacognitive skills opens opportunities for training those skills, initially within but eventually across learning contexts through 'high road' transfer (Salomon, 1989).

The process of thinking in constructivist paradigm requires higher order skills, devolving deeper and harder into content and context (Black \& McClintock, 1995). Using a computer as a cognitive tool supports the external construction of cognitive processes "in assisting learners in accomplishing complex cognitive tasks" (Kozma, 1987).

Cognitive tools, along with constructivist learning environments, guide and activate cognitive learning strategies and critical thinking (Jonassen, 1994). They can enhance the cognitive powers of learners during their thinking, problemsolving, and learning (Jonassen \& Reeves, 1996).

A student who uses a cognitive tool effectively should engage (actively), think (deeply), and articulate his/her knowledge (Jonassen, 1994).

Modern technologies provide us with both cognitive and metacognitive skills that are based upon a constructivist epistemology. Constructivist theory of learning states that learning is achieved by "the active construction of knowledge supported by various perspectives within meaningful contexts and social interactions" (Oliver, 2002). How we construct knowledge depends upon what we already know, our previous experiences, how we have organized those experiences into knowledge structures such as (mental models), and the beliefs that we use to interpret our own realities that we encounter in the world.

The computer's role in education has been largely viewed as an instructional tool and for providing a richer and more exciting learning environment (Duffy \& Cunningham 1996; Jonassen \& Reeves, 1996). 
By integrating technology with constructivist methods, such as problem-based learning and project-based learning, learners are more responsible and active in the learning process. By focusing on the learner, the role of technology can support new understandings and capabilities, thus, offering a (meta)cognitive tool to support cognitive and metacognitive processes which enhance learning by guiding learner's thinking, and helping the learner go through the problem solving, decision making, exploring, collaborative learning and critical thinking.

\section{Constructivist Learning Environments}

Within the paradigm shift from the objectivist to the constructivist pedagogy, technologies play an integral part in the learning environment (Duffy \& Cunningham, 1996). These environments create engaging and content-relevant experiences by utilizing ICTs and resources to support unique learning goals and knowledge construction (Young, 2003).

"The richness of the technology permits us to provide a richer and more exciting (entertaining) learning environment... our concern is the new understandings and new capabilities that are possible through the use of technology" (Duffy \& Cunningham, 1996). By integrating technology with constructivist methods, such as problem-based learning and project-based learning, learners are more responsible and active in the learning process" (Grant, 2002).

Wilson (1995) defines a constructivist learning environment as "a place where learners may work together and support each other as they use a variety of tools and information resources in their pursuit of learning goals and problemsolving activities." It is the environment that allows learner-centred activities to take place where the teacher provides the students with experiences in order to develop problem-solving, critical-thinking and creative skills, and apply them in a meaningful manner.

In technology-supported learning environments "students join in manipulating materials and, thus, create a community of learners who built their knowledge together" (Dewey, 1966). Hence, Dewey proposes a method of "directed living", which means that students are engaged in real-world, practical workshops in which they would demonstrate their knowledge through creativity and collaboration. Dewey developed the first pedagogical constructivist approach to teaching and learning that he called learning by doing, learning through practical experience (experiential learning).

The other implication for the construction of technology-supported learning environments is the need to embed learning into authentic and meaningful contexts (Brown et al., 1989). Brown et al. (1989) argue that knowledge, learning, and cognition are fundamentally situated in activity, context, culture, and situations. In this sense, constructivist epistemology explains that knowledge, learning, and cognition, as social constructions, are expressed on the basis of the interaction with their environment. In such an environment the use of technologies can enable constructivist innovations in the classroom contributing to the realization of meaningful, authentic, active, interactive and problem-based learning. Students search solutions to real world problems which based on a technology framework lead to critical and analytical thinking.

Closely connected with the previous statement is Situated Learning (Lave \& Wenger, 1991), as a new paradigm of learning which emphasizes the importance of learning within meaningful context (Duffy \& Jonassen, 1991, Perkins, 1991)). Learning could only be achieved through meaningful activity, learning is a continuous, life-long process resulting from acting in situations (Brown, 1989, p.33). Context is significant as it treats meaningful and relevant situations, and provides learners with the opportunity to construct new knowledge from authentic experience.

According to Jonassen (1995), constructivist learning environments engage learners in knowledge construction through collaborative activities that embed learning in a meaningful context and through reflection on what has been learned through conversation with other learners.

Construction of new knowledge (new ideas or concepts) based upon their prior knowledge, is the result of "an active process of articulation and reflection within a context" (Brown et al., 1989, Duffy and Jonassen, 1991). The knowledge that is created is a product of the mind and results from the individual's experiences with and interpretations of the context (Jonassen, 1991). Context includes features of the real-world setting in which the task to be learned might naturally be accomplished. The constructivist classroom relies heavily on collaboration among students throughout the learning process. Collaborative learning emphasizes the active participation of students in a collaborative learning setting. Students have the opportunity to discuss with peers, to be actively engaged in the learning process. Thus, a goal of collaborative learning is to shift learning from a teacher-centred to a student-centred methodology. Through collaboration and cooperation with others, students are engaged in learning that is authentic, holistic, and challenging. Conversation is forced by collaboration; it is an important part of the meaning-making process. It refers to interaction and communication between the teacher and students as well as among students. 
A study conducted by Butler-Pascoe and Wiburg (2003) presents several advantages of the successful Technology-Enhanced Language Learning Environment (TELLE) which have been found their place in the constructivist foreign language classroom. A foreign language environment that utilizes technology:

- provides interaction and learning activities representative of specific professional or academic environments

- provides authentic comprehensible field-specific input for language learning and facilitates student production. It supports development of cognitive abilities (thinking, reasoning, perception, "more creative and flexible problem solving" - Perkins, 1991)

- $\quad$ supports collaborative learning (interacting through computers)

- emphasizes the importance and the implication of the learning-centred approach

- $\quad$ addresses specific needs of the learner (Hutchinson and Waters, 1987; Dudley-Evans, \& St. John, 1998)

- facilitates the acquisition of language skills

- uses multiple modalities to support different learning styles

- provides appropriate feedback and assessment of content knowledge and English skills.

Constructivism proposes that learning environments should support multiple perspectives or interpretations of reality, knowledge construction, context-rich and experience-based activities (Jonassen, 1991). These are tasks which have "real-world relevance and utility, that integrate those tasks across the curriculum, that provide appropriate levels of difficulty or involvement" (Jonassen, 1991).

\section{New Teacher Competencies}

The era of globalization has brought new challenges involving meaningful ways to incorporate digital technologies into the classroom. Technology-enhanced constructivist classroom encourages the teacher play a new significant and valuable role.

McLoughlin \& Oliver (1998) define pedagogical roles for teachers in a technology-supported classroom, including settings of joint tasks, rotating roles, promoting student to be self manager, supporting metacognition, fostering multiple perspectives and scaffolding learning. The teacher creates social and intellectual climates, where collaborative and cooperative learning methods are supported. The teacher creates opportunities for students to interact with other learners, with the teacher, and the content.

Hence, the teacher is no longer perceived as "primary knower" (Berry, 1981), knowledge dispenser and decision maker. Instead, the teacher is the facilitator of learning, one who "facilitates the acquisition of knowledge" (Brookfield, 1985), one whose main function is to help students become active participants in their learning process. The teacher is responsible for leading and coordinating the work and make learning progress easier.

Besides, the teacher is the supporter, one who supports the learner by means of suggestions that arise out of ordinary activities, by challenges that inspire creativity, and with projects that allow for independent thinking and new ways of learning information.

In Vygotsky's (1978) theory of constructivism, the teacher serves as the mediator who coaches and encourages students to formulate their own level of understanding.

In the Bruner's (1979) classroom, the teacher is the instructor, (direct and guide the learning process) who should try and encourage students to discover principles by themselves. The instructor and student should engage in an active dialog (Socratic learning). The task of the instructor is to translate information to be learned into a format appropriate to the learner's current state of understanding.

We have to agree with Crystal (2003) who claims that the actor and the teacher inhibit the same stable. They both have to put on a show (the actor on a stage and the teacher in the classroom).

In order to summarize the key roles of the constructivist teacher, we turn to Brooks and Brooks (1993) statement. Therefore, the constructivist teacher:

- encourages and accepts student autonomy and initiative,

- uses a wide variety of materials, including raw data, primary sources, and interactive materials and encourage students to use them,

- inquires about students' understandings of concepts before sharing his/her own understanding of those concepts,

- encourages students to engage in dialogue with the teacher and with one another,

- encourages student inquiry by asking thoughtful, open-ended questions and encourages students to ask questions to each other and seek elaboration of students' initial responses, 
- engages students in experiences that show contradictions to initial understandings and then encourage discussion,

- provides time for students to construct relationships and create metaphors,

- assesses students' understanding through application and performance of open-structured tasks.

Based on the above mentioned characteristics, we can say that modern technology within constructivist theory requires a teacher whose main function is to help students become active participants in their learning and make meaningful connections between prior knowledge, new knowledge, and the processes (Copley, 1992) involved in the technology-based classroom.

\section{Student-Centred Approach}

In the world of competition the focus of modern foreign language learning is on practical experience and direct activity of students. Technology-enhanced classrooms tap constructivist strategies (Jonassen, 1999) where students actively construct knowledge, make meaningful connections between prior knowledge, new knowledge, and the processes involved in learning' (Copley, 1992).

Students actively involve their cognitive structures in schema building experiences (Fosnot, 1996). Their knowledge, skills, strategies, and motivation for learning are of prime importance (Hutchinson \& Waters, 1987).

Jonassen (1991) states that learners must be given opportunities to be active in ways that will promote selfdirection, creativity and critical analysis of problems requiring a solution. affirm that "learning becomes a continuous, lifelong process which results from acting in situations" (Brown et al., 1989).

Learners function as designers using the technology as tools for analyzing the world, accessing information, interpreting and organizing their personal knowledge, and representing what they know to others" (Jonassen, 1994). Technological tools such as spreadsheets, databases, expert systems, video conferencing and others can be used by students to analyze subject matter, develop representative mental models, and then transcribe them into knowledge bases (Jonassen, 1994; Jonassen \& Carr, 2000).

By focusing on the learner, digital technologies support cognitive and metacognitive processes which enhance learning by guiding learner's thinking, and by helping the learner go through the problem solving, decision making, exploring, collaborative learning and critical thinking.

"When students work with technology (and not from technology), they enhance the capabilities of the computer, and the computer enhances their thinking and learning" (Jonassen, 1994). This interaction empowers learners to become active and responsible. Cognitive tools should allow students to "activate metacognitive learning strategies" (Jonassen, 1994) and "to assist learners in accomplishing complex cognitive tasks" (Kozma, 1991).

Cognitive tools can enhance the cognitive powers of learners during their thinking, problem-solving, and learning (Jonassen \& Reeves, 1996).

The effectiveness of constructivist methods and technology on student learning outcomes is dependent on how the technology is integrated into the instruction and the assessment of learning outcomes. Assessment is defined as "all those activities undertaken by teachers and/or by their students, which provide information to be used as feedback to modify the teaching and learning activities in which they are engaged" (Black \& Wiliam, 1998). Portfolio is considered authentic assessment as it provides evidence of what a student can actually do, more specifically, to show student's progress and achievement. It provides structure for involving students in developing standards for quality performance and it improves students' cognitive and metacognitive abilities to understand their own learning processes.

\section{Conclusion}

The paper provides a brief overview of modernization of foreign language teaching/learning process through the theoretical framework of constructivism. It reports on the digital foreign language learning environment that is learnercentred, knowledge-centred, assessment-centred and community centred (Bransford et al., 2000). The environment creates engaging and content-relevant experiences by utilizing modern technologies and resources to support unique learning goals and knowledge construction (Young, 2003). The utilization of technology in the constructivist classroom enables students to be more responsible and active in the learning process, which contributes to an increase in learning outcomes. Central to the tenet of constructivism is that learning is an active process in which learners construct new knowledge based upon their prior knowledge through the interaction with the environment. Computers and the Internet, 
as powerful cognitive and metacognitive tools, may help in transforming the traditional teacher-centred and text-bound classrooms into student-focused, interactive knowledge environments.

Through language teaching/learning strategies based on constructivist approach, and with the use of digital technologies as an important language medium (Živković \& Stojković, 2012), students will impose their voices on the world by being aware of the intricate nature of the language and the importance of modern technologies in the era of globalization, in the formation of our presence and future.

Only by modernizing our foreign language teaching/learning process can we await positive results. So, To Modernize or Not to Modernize - There is No Question (Crystal and Crystal, 2002 - adapted from Shakespeare's Words).

\section{References}

Berry, M. (1981). "Systemic linguistics and discourse analysis: A multi-layered approach to exchange structure" in Coulthard, R. M. and Montgomery, M. M. (eds.) Studies in Discourse Analysis. London: Routledge and Kegan Paul, pp 120 - 145

Black, P. and Wiliam, D. (1998). Assessment and classroom learning. In Assessment in Education, 5:1, pp. 7-74.

Bransford, J.D., A.L. Brown, A.L., and R.R. Cocking (eds). (2000). How People Learn: Brain, Mind, Experience, and School. National Academy of Sciences, Washington, D.C.

Brookfield, S.D., editor, (1985). Self-Directed Learning: From Theory to Practice. New

Directions for Adult and Continuing Education. Jossey-Bass Publishers, San

Francisco, CA.

Brooks, J.G., \& Brooks, M.G. (1993). In search of understanding: The case for construc-

tivist classrooms. Alexandria, VA: Association for Supervision and Curriculum Develop- ment.

Brown, J. S., Collins, A., \& Duguid, P. (1989). Situated cognition and the culture of learning. Educational Researcher, 19(1), 32-42.

Bruner, J. S. (1979). On knowing : essays for the left hand (Expanded ed.). Cambridge, MA: Belknap Press of Harvard University Press.

Butler-Pascoe, M.E. and Wiburg, K. M. (2003). Technology and Teaching English Language Learners. New York. Pearson Education, Inc.

Copley, J. (1992). The integration of teacher education and technology: a constructivist model. In D. Carey, R. Carey, D. Willis, and J. Willis (Eds.), Technology and Teacher Education, Charlottesville, VA: AACE, 681.

Crystal, D. and Crystal, B. (2002). Shakespeare's Words: A Glossary and Language Companion. London: Penguin.

Crystal, D. (2003). English as a global language (2nd ed). Cambridge: Cambridge University Press.

Dewey, John. (1966). Democracy and Education. New York: Free Press.

Dudley-Evans, T., \& St. John, M. J. (1998). Developments in English for specific purposes: A multi-disciplinary approach. Cambridge, Cambridge University Press.

Duffy, T.M., \& Jonassen, D.H. (1991). "Constructivism: New implications for

instructional technology?" Educational Technology, 31(5), 7-11.

Duffy, T. M., \& Cunningham, D. J. (1996). Constructivism: Implications for the design and delivery of instruction. In D. H. Jonassen (Ed.), Educational communications and technology (pp. 170-199). New York: Simon \& Schuster Macmillan.

Flavell, J. H. (1979). Metacognition and cognitive monitoring: A new area of cognitive-developmental inquiry. American Psychologist, 34, 906-911.

Fosnot, C. T. (1996). Constructivism: Theory, perspective, and practice. New York: Teachers College Press.

Gibbs, G. (1999). (Ed), Improving student learning using research to improve student learning, Oxford: Oxford Centre for Staff Development, pp. 3-10.

Giddens, A. (1990). The Consequences of Modernity, Polity Press, Cambridge.

Grant, M. M. (2002). Getting a grip on project-based learning: Theory, cases and recommedations. Meridian: A Middle School Computer Technologies Journal, 5(Winter).

Heafner, T. L., \& McCoy, L. P. (2001). Technology and the academic and social culture of a university campus. In J. Price, D. Willis, N. Davis, \& J. Willis (Eds.), Proceedings of the Society for Information Technology in Teacher Education 01. Charlottesville, VA:

Association for the Advancement of Computing in Education.

Hutchinson, T., \& Waters, A. (1987). English for specific purposes. Cambridge: CUP.

Jonassen, D. (1991). Evaluating constructivistic learning. Educational Technology, 31(10), (pp. 28-33).

Jonassen, D. H. (1994). Technology as Cognitive Tools: Learners as Designers. Retrieved from ITFORUM: http://itech1.coe.uga.edu litforum/paper1/paper1.html

Jonassen, D.H. (1995). Supporting communities of learners with technology: A vision for integrating technology with learning in schools. Educational Technology, 35(4), 60-63.

Jonassen, D., \& Reeves, T. (1996). Learning with technology: Using computers as cognitive tools. In D. H. Jonassen (Ed.), Handbook of research in educational communications and technology (pp. 693-719). New York: Simon \& Schuster Macmillan.

Jonassen, D. (1999). Designing constructivist learning environments. In C. Reigeluth (Ed.), Instructional design theories and models: A new paradigm of instructional theory (Vol. II, pp. 215-239). Mahwah, NJ: Lawrence Erlbaum Associates.

Jonassen, D.H. (2000). Computers as Mind Tools for Schools: Engaging Critical Thinking. Columbus, Prentice- Hall, Ohio.

Kozma, Robert B. (1991). Learning with Media. Review of Educational Research 61 (Summer 1991): 179-211. 
Lave, J. \& Wenger, E. 1991. Situated learning: Legitimate peripheral participation. Cambridge UK: Cambridge University Press.

Livingston, J. (1997). Metacognition: An Overview. State University of New York at Buffalo [Electronic version]. http://www.gse.buffalo.edu/fas/shuell/cep564/Metacog.htm. Last viewed 10/29/08.

McLoughlin, C., \& Oliver, R. (1998). Scaffolding Higher Order Thinking in A Tele-Learning Environment. Ottmann, T. \& Tomek, I. (Eds.). Proceedings of Ed-Media/Ed-Telecom 98 world conference on educational multimedia and hypermedia \& world conference on educational telecommunications, 977-983.

Oliver R. (2002). The role of ICT in higher education for the 21st century: ICT as a change agent for education. Retrieved April 14, 2007. http://elrond.scam.ecu.edu.au/oliver/2002/he21.pdf

Perkins, D. (1991). Technology meets constructivism: Do they make a marriage? Educational Technology, 31(5), 18-23.

Salomon, G. (1993). On the nature of pedagogic computer tools. The case of the wiring partner. In S.P. LaJoie \& S.J. Derry (Eds.), Computers as cognitive tools. Hillsdale, NJ: Lawrence Erlbaum Associates.

Stojković, N., \& Živković, S. (2012). Advocating the Need for Incorporating Critical Pedagogy and Critical Literacy in Teaching English for Specific Purposes, US-China Foreign Language, USA \& Sino-US English Teaching.

Vygotsky, L. S. (1978). Mind in society: The development of higher psychology process. Cambridge, MA: Harvard University Press. (Original published in 1930).

Wilson, B.G. (Ed.), (1995). Constructivist learning environments. Englewood Cliffs, NJ: Educational Technology Publications.

Young, LD. (2003). Bridging Theory and Practice: Developing Guidelines to Facilitate the Design of Computer-based Learning Environments. Canadian J. Learn. Technol, 29(3), Fall/Autumn.Retrieved May 14, 2007, from http://www.cjlt.cal

Živković, S. \& Stojković, N. (2011). Modernization of English as foreign language studies in university education, u zborniku radova University Education in Transition, Transition in University Education - Modern and Universal, Belgrade.

Živković, S. \& Stojković, N. (2012). English for Students of Information and Communication Technologies, Elektronski fakultet, Niš. 